\title{
Association between genetic variants in CD1A and CD1D genes and pulmonary tuberculosis in an Iranian population
}

\author{
MOHSEN TAHERI $^{1,2}$, HIVA DANESH $^{3}$, FATEMEH BIZHANI $^{3}$, GHOLAMREZA BAHARI $^{4}$, \\ MOHAMMAD NADERI ${ }^{5}$ and MOHAMMAD HASHEMI ${ }^{1,3}$ \\ ${ }^{1}$ Genetics of Non-Communicable Disease Research Center; ${ }^{2}$ Department of Genetics, School of Medicine; \\ ${ }^{3}$ Department of Clinical Biochemistry, School of Medicine; ${ }^{4}$ Children and Adolescent Health Research Center; \\ ${ }^{5}$ Infectious Diseases and Tropical Medicine Research Center, \\ Zahedan University of Medical Sciences, Zahedan 98167-4318, Iran
}

Received November 27, 2018; Accepted March 12, 2019

DOI: $10.3892 /$ br.2019.1201

\begin{abstract}
Cluster of differentiation (CD)1 molecules are a highly conserved family of $\mathrm{MCH}$-like transmembrane glycoproteins that bind lipid and glycolipid antigens and present a diverse range of microbial and self-glycolipids to antigen-specific $\mathrm{T}$ cells. The current study aimed to find out the impact of CD1A and CD1D polymorphisms on pulmonary tuberculosis (PTB). This case-control study encompassed 172 PTB patients and 180 healthy subjects. Genotyping of CD1A and CD1D variants was achieved using the polymerase chain reaction restriction fragment length polymorphism method. The results revealed that CD1A rs411089 variant significantly increased the risk of PTB in recessive model [odds ratio $(\mathrm{OR})=2.71,95 \%$ confidence interval $(\mathrm{CI})=1.38-5.57$, $\mathrm{CC}$ vs. $\mathrm{TT}+\mathrm{TC}, \mathrm{P}=0.005]$. CD1D rs859009 polymorphism significantly reduced the risk of PTB in heterozygous codominant $(\mathrm{OR}=0.50,95 \% \mathrm{CI}=0.29-0.86, \mathrm{P}=0.011, \mathrm{GC}$ vs. $\mathrm{GG})$ and dominant $(\mathrm{OR}=0.53,95 \% \mathrm{CI}=0.31-0.88, \mathrm{P}=0.019$, $\mathrm{GC}+\mathrm{CC}$ vs. GG) inheritance model. The CD1A rs366316, CD1D rs973742 and CD1D rs859010 were not associated with the risk/protection from PTB $(\mathrm{P}>0.05)$. The results of the present study suggest that CD1A rs411089 and CD1D rs859009 but not CD1A rs366316, CD1D rs973742 and CD1D rs859010 polymorphisms are associated with PTB in a sample of the Iranian population. Further investigation with different ethnicities and larger sample sizes are necessary to certify the findings of the present study.
\end{abstract}

Correspondence to: Professor Mohammad Hashemi, Department of Clinical Biochemistry, School of Medicine, Zahedan University of Medical Sciences, Khalij Fars Boulevard, 1 Jannat Street, Zahedan 98167-4318, Iran

E-mail: mhd.hashemi@gmail.com; hashemim@zaums.ac.ir

Key words: tuberculosis, cluster of differentiation 1A, cluster of differentiation 1D, polymorphism

\section{Introduction}

Mycobacterium tuberculosis (MTB) is respiratory tract infectious disease but can affect nearly all of the body, including the brain, the kidneys and the bones (1). Tuberculosis is still a major health problem and a leading cause of mortalities from infectious disease throughout the world (2). Based on a World Health Organization report 10.4 million new TB cases and 1.3 million fatalities occurred in 2016 globally (3). The prevalence of TB in Sistan and Baluchistan province is higher than other provinces of Iran. Whereas one-third of the world's population is infected with MTB, 5-10\% of infected cases go on to develop active $\mathrm{TB}$, which indicates that in addition to the environment host genetics factors may influence the risk of the disease $(2,4,5)$.

Cluster of differentiation 1 (CD1) genes, mapped to human chromosome 1 (1q23.1), encoding five isoforms of the CD1 molecule, namely CD1a, CD1b, CD1c, CD1d and CD1e (6-9). CD1 is a family of glycoproteins which are expressed on antigen presenting cells (APCs) (10). They are belongs to major histocompatibility complex class I (MHC) and participate in presentation of lipid antigens to T cells (11) but unlike MHCs their expression is nearly identical in all humans (11). The CD1 family can be divided into three groups. Group 1 consists of CD1a, CD1b and CD1c that present lipid antigens to T-helper cells. CD1D belongs to group 2 and presents lipid antigens to natural killer T cells and group 3 that composed of CD1E (12).

It is clear that CD1 molecules participate in cell-mediated immune responses against MTB (13). Indeed, several kinds of mycobacterial lipids function as antigens in this system (11). CD1-restricted T cells identify MTB and react to mycobacterium cell wall lipid antigens (14). CD1 molecules, unlike classical MHC molecules, exhibit limited polymorphism $(10,15)$ but, these few polymorphisms are demonstrated to be associated with susceptibility or resistance to certain diseases $(12,14,16,17)$. Single nucleotide polymorphism (SNPs), the most common type of genetic variants can affect the expression and function of the gene $(18,19)$. There is little data regarding the impact of CD1 gene polymorphisms and tuberculosis susceptibility (14). Seshadri et al (14) investigated the association between rs366316, rs2269714, rs411089 and rs389293 polymorphisms of CD1A gene and 
risk of tuberculosis. They reported that rs411089 and rs366316 variants were significantly correlated with the development of tuberculosis. To the best of our knowledge, no study investigated the impact of CDID polymorphisms on tuberculosis susceptibility. The present study aimed to examine the association between CD1A (rs411089 and rs366316) and CD1D (rs973742, rs859009 and rs859010) polymorphisms and the risk of PTB in a sample of the southeast Iranian population.

\section{Materials and methods}

Patients. A total of 352 subjects including 172 clinically diagnosed patients with pulmonary tuberculosis (PTB) between 12 and 86 years of age (69 males and 103 females), and 180 unrelated healthy individuals ranging between 20 and 85 years of age (74 males and 106 females) were recruited in the study from May 2014 to March 2018. The cases were selected from PTB patients admitted to the University Affiliated Hospital (Bouali Hospital, Zahedan, Iran; referral center for TB). The diagnosis of PTB depended on clinical findings, radiological evidence, positive smear for MTB, culture and response to antituberculosis chemotherapy as described previously (20-23). The control individuals did not have a history of TB and inflammatory disease or other of chronic infectious disease; they were of the same ethnicity as patients and living in the same area as the patients with PTB (Southeast Iran). The local Ethics Committee of the Zahedan University of Medical Sciences (Zahedan, Iran) approved the project and written informed consent was taken from all participants. Blood samples $(5 \mathrm{ml})$ were collected in Na-EDTA tubes from patients and healthy controls and stored at -20 until DNA extraction. Genomic DNA was extracted from whole blood by salting-out method as described previously (24).

Genotyping. Genotyping of CD1A and CD1D was achieved by polymerase chain reaction amplification-restriction fragment length polymorphism assays. The primers were synthesized by Metabion International AG (Erding, Germany) and the restriction enzyme were purchased from Fermentas; Thermo Fisher Scientific, Inc. (Waltham, MA, USA). Primer sequences restriction enzymes and length of the fragments are summarized in Table I. Amplification was achieved in a final volume of $20 \mu \mathrm{l}$ containing $1 \mu \mathrm{l}$ genomic DNA ( 100 ng/ml), $1 \mu \mathrm{l}$ each primer $(10 \mu \mathrm{M})$ and $10 \mu \mathrm{l}$ of $2 \mathrm{X}$ Prime Taq Premix (Genet Bio,

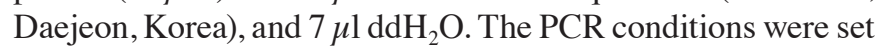
as follows: $95^{\circ} \mathrm{C}$ for $5 \mathrm{~min}, 30$ cycles of $95^{\circ} \mathrm{C}$ for $30 \mathrm{sec}, 62^{\circ} \mathrm{C}$ for CD1A rs411089, CD1D rs859009 and CD1D rs859010, $60^{\circ} \mathrm{C}$ for $\mathrm{CD} 1 \mathrm{D}$ rs $973742,65^{\circ} \mathrm{C}$ for $\mathrm{CD} 1 \mathrm{~A}$ rs 366316 and $72^{\circ} \mathrm{C}$ for $30 \mathrm{sec}$ and a final extension step of $72^{\circ} \mathrm{C}$ for $5 \mathrm{~min}$. Then, $10 \mu \mathrm{l}$ of PCR product was digested with suitable restriction enzyme (Table II) and resolved on $2.5 \%$ agarose gel containing $0.5 \mu \mathrm{g} / \mathrm{ml}$ ethidium bromide and visualized under UV light. A total of $\sim 10 \%$ of the random samples were regenotyped and the finding were confirmed as $100 \%$ concordant.

Statistical analysis. Analysis of the data was achieved by the statistical package SPSS 20 software (IBM Corp., Armonk, NY, USA). Association among variants and PTB risk was estimated by calculation the odds ratio (OR) and 95\% confidence intervals (CI) from logistic regression analysis. The Bonferroni correction test was performed by multiplying
P-values of logistic regression analysis by the number of SNPs examined for each gene.

Haplotype analysis was executed using SNPStats: A web tool for the analysis of association studies (25). $\mathrm{P}<0.05$ was considered to indicate a statistically significant difference.

The observed genotype frequencies in the controls were examined for Hardy-Weinberg equilibrium (HWE) using the $\chi^{2}$-test. The Bonferroni correction test was performed by multiplying P-values by the number of SNPs examined for each gene.

\section{Results}

Patients. The study participants include 172 patients with PTB (69 males and 103 females; mean age, 50.01 20.57 years) and 180 healthy individuals (74 males and 106 females; mean age, $49.92 \pm 15.10$ years). There was no statistically significant difference between the groups regarding sex and age $(\mathrm{P}=0.486$ and 0.572 , respectively).

Association between the CDIA variants and PTB risk. The genotype and allelic frequencies of CD1A rs411089 and CD1A rs366316 gene polymorphisms in cases and controls are presented in Table II. The results demonstrated that the CC genotype of CD1A rs411089 polymorphism in recessive inheritance model increased the risk of PTB in comparison with $\mathrm{TT}+\mathrm{TC}$ genotypes $(\mathrm{OR}=2.71,95 \% \mathrm{CI}=1.36-5.40, \mathrm{P}=0.004)$. As presented in Table II there was no significant difference in genotype and allelic distribution of CD1A rs366316 gene polymorphisms between PTB patients and controls $(\mathrm{P}>0.05)$.

Association between the CDID variants and PTB risk. Table III summarized the genotype and allele frequencies of CD1D rs973742, CD1D rs859009 and CD1D rs859010 polymorphisms in PTB patients and the control groups. The GC genotype as well as the $\mathrm{GC}+\mathrm{CC}$ genotype of CD1D rs859009 polymorphism decreased the risk of PTB $(\mathrm{OR}=0.49$, $95 \% \mathrm{CI}=0.29-0.85, \mathrm{P}=0.01$ and $\mathrm{OR}=0.53,95 \% \mathrm{CI}=0.31-0.89$, $\mathrm{P}=0.01$, respectively). The allele frequency of CD1D rs859009 Polymorphism was not significantly different between the groups $(\mathrm{P}=0.22)$. The genotype and allele frequencies of CD1D rs973742 and CD1D rs859010 were not significantly different between two groups $\left(\chi^{2}=2.206, P=0.332\right.$ and $\chi^{2}=2.252$, $\mathrm{P}=0.324$, respectively). The results demonstrated that CD1D rs973742 and CD1D rs859010 variants were not associated with risk of/protection from PTB in codominant, dominant and recessive tested inheritance models (Table II). The results demonstrated that the rs366316, rs859010 polymorphisms but not rs411089, rs973742 and rs859009 polymorphisms were in present in HWE, Tables II and III).

Haplotypes analysis. Haplotypes analysis was achieved (Table IV) and the results demonstrated that haplotypes TGACA, TAACA, and TAAGA significantly decreased the risk of PTB in comparison with CAGGA (rs411089C/rs366316A/ rs973742G/rs859009G/rs859010A).

\section{Discussion}

CD1 is a family of antigen presenting molecules that belongs to the MHC class I molecules but, unlike those that exist on 
Table I. Primer sequences of polymerase chain reaction-restriction fragment length polymorphism for detection of CD1A and CD1D polymorphisms.

\begin{tabular}{|c|c|c|c|}
\hline & $\begin{array}{l}\text { Primer sequences } \\
\qquad\left(5^{\prime}-3^{\prime}\right)\end{array}$ & $\begin{array}{l}\text { Restriction } \\
\text { enzyme }\end{array}$ & Fragment (bp) \\
\hline \multirow[t]{2}{*}{ CD1A rs411089 } & F: TGTGTGTGGTTTCCCTAGCA & \multirow[t]{2}{*}{ BseGI } & T allele: 297 \\
\hline & R: CGATCCAGGTGACATGGAAG & & C allele: $205+92$ \\
\hline \multirow[t]{2}{*}{ CD1A rs366316 } & F: TGGGAAAATATTGAAAAGGACAG & \multirow[t]{2}{*}{$A l W 26 \mathrm{I}$} & G allele: 401 \\
\hline & R: ATTGGTCTTTGATTTCTGTTCCA & & A allele: $254+147$ \\
\hline \multirow[t]{2}{*}{ CD1D rs973742 } & F: TGGGGAGTCTGCCATAATAGA & \multirow[t]{2}{*}{ TaiI } & A allele: 502 \\
\hline & R: TGCCCATTTATTATCTGAATGTTG & & G allele: $273+229$ \\
\hline \multirow[t]{2}{*}{ CD1D rs859009 } & F: TGGCTGTCCAGGTACACACT & \multirow[t]{2}{*}{ MwoI } & $\mathrm{G}$ allele 440 \\
\hline & R: GCAGTACATGTCTCTAGGTGGAA & & $\mathrm{C}$ allele 338,102 \\
\hline \multirow[t]{2}{*}{ CD1D rs859010 } & F: TGGCTGTCCAGGTACACACT & \multirow[t]{2}{*}{$A L w 26 \mathrm{I}$} & A allele 152,271 \\
\hline & R: GCAGTACATGTCTCTAGGTGGAA & & $\mathrm{T}$ allele 423 \\
\hline
\end{tabular}

$\mathrm{CD}$, cluster of differentiation; $\mathrm{F}$, forward; $\mathrm{R}$, reverse.

Table II. The genotypes and allele frequency distribution of CD1A polymorphism in pulmonary tuberculosis patients and control groups.

\begin{tabular}{|c|c|c|c|c|c|c|}
\hline Polymorphism & $\begin{array}{l}\text { Patients } \\
\mathrm{n}(\%)\end{array}$ & $\begin{array}{c}\text { Controls } \\
\mathrm{n}(\%)\end{array}$ & OR $(95 \% \mathrm{CI})$ & P-value & $\mathrm{P}^{\mathrm{C}}$ & $\begin{array}{c}\text { HWE } \\
\text { (P-value) }\end{array}$ \\
\hline CD1A rs411089 & & & & & & 0.000 \\
\hline \multicolumn{7}{|l|}{ Codominant } \\
\hline TT & $21(12.2)$ & $20(11.1)$ & 1.00 & - & - & \\
\hline $\mathrm{TC}$ & $121(70.3)$ & $147(81.7)$ & $0.78(0.41-1.47)$ & 0.503 & - & \\
\hline $\mathrm{CC}$ & $30(17.5)$ & $13(7.2)$ & $2.20(0.89-5.25)$ & 0.118 & - & \\
\hline \multicolumn{7}{|l|}{ Dominant } \\
\hline TT & $21(12.2)$ & $20(11.1)$ & 1.00 & & & \\
\hline $\mathrm{TC}+\mathrm{CC}$ & $151(87.8)$ & $160(88.9)$ & $0.90(0.48-1.69)$ & 0.868 & - & \\
\hline \multicolumn{7}{|l|}{ Recessive } \\
\hline $\mathrm{TT}+\mathrm{TC}$ & $142(82.5)$ & $167(92.8)$ & 1.00 & & & \\
\hline $\mathrm{CC}$ & $30(17.5)$ & $13(7.2)$ & $2.71(1.38-5.57)$ & 0.005 & 0.010 & \\
\hline \multicolumn{7}{|l|}{ Alleles } \\
\hline $\mathrm{T}$ & $163(47.4)$ & 187 (51.9) & 1.00 & & & \\
\hline $\mathrm{C}$ & $181(52.6)$ & $173(48.1)$ & $1.20(0.89-1.61)$ & 0.221 & - & \\
\hline CD1A rs366316 & & & & & & 0.079 \\
\hline \multicolumn{7}{|l|}{ Codominant } \\
\hline $\mathrm{AA}$ & $70(40.7)$ & $61(33.9)$ & 1.00 & & & \\
\hline AG & $81(47.1)$ & 97 (53.9) & $0.73(0.46-1.14)$ & 0.205 & - & \\
\hline GG & $21(12.2)$ & $22(12.2)$ & $0.83(0.42-1.66)$ & 0.725 & & \\
\hline \multicolumn{7}{|l|}{ Dominant } \\
\hline $\mathrm{AA}$ & 70 (40.7) & $61(33.9)$ & 1.00 & & & \\
\hline $\mathrm{AG}+\mathrm{GG}$ & $102(59.3)$ & $119(66.1)$ & $0.74(0.48-1.16)$ & 0.225 & - & \\
\hline \multicolumn{7}{|l|}{ Recessive } \\
\hline $\mathrm{AA}+\mathrm{AG}$ & $151(47.8)$ & $158(87.8)$ & 1.00 & & & \\
\hline GG & $21(12.2)$ & $10(12.2)$ & $2.20(1.05-4.62)$ & 0.058 & - & \\
\hline \multicolumn{7}{|l|}{ Alleles } \\
\hline A & $221(64.2)$ & $219(60.8)$ & 1.00 & & & \\
\hline $\mathrm{G}$ & $123(35.8)$ & $141(39.2)$ & $0.86(0.64-1.17)$ & 0.391 & - & \\
\hline
\end{tabular}

The association was performed using logistic regression analysis. HWE was tested by $\chi^{2}$ test. OR, odds ratio; CI, confidence interval; $\mathrm{P}^{\mathrm{C}}$, Bonferroni corrected P-value; HWE, Hardy-Weinberg equilibrium; CD, cluster of differentiation. 
Table III. The genotypes and allele distribution of CD1D polymorphisms in pulmonary tuberculosis patients and control groups.

\begin{tabular}{|c|c|c|c|c|c|c|}
\hline Polymorphism & $\begin{array}{c}\text { Patients } \\
\mathrm{n}(\%)\end{array}$ & $\begin{array}{l}\text { Controls } \\
\mathrm{n}(\%)\end{array}$ & OR $(95 \% \mathrm{CI})$ & P-value & $\mathrm{P}^{\mathrm{C}}$ & $\begin{array}{c}\text { HWE } \\
\text { (P-value) }\end{array}$ \\
\hline CD1A rs973742 & & & & & & 0.000 \\
\hline \multicolumn{7}{|l|}{ Codominant } \\
\hline AA & $61(35.5)$ & $67(37.2)$ & 1.00 & - & - & \\
\hline $\mathrm{AG}$ & $93(54.1)$ & $102(56.7)$ & $1.00(0.64-1.56)$ & 0.999 & - & \\
\hline GG & $18(10.4)$ & $11(6.1)$ & $1.80(0.76-3.91)$ & 0.217 & - & \\
\hline \multicolumn{7}{|l|}{ Dominant } \\
\hline $\mathrm{AA}$ & $61(35.5)$ & $67(37.2)$ & 1.00 & & & \\
\hline $\mathrm{AG}+\mathrm{GG}$ & $111(64.5)$ & $113(62.8)$ & $1.08(0.69-1.68)$ & 0.741 & - & \\
\hline \multicolumn{7}{|l|}{ Recessive } \\
\hline $\mathrm{AA}+\mathrm{AG}$ & $154(89.6)$ & $169(93.9)$ & 1.00 & & & \\
\hline GG & $18(10.4)$ & $11(6.1)$ & $1.80(0.84-4.05)$ & 0.175 & - & \\
\hline \multicolumn{7}{|l|}{ Alleles } \\
\hline A & $215(62.5)$ & $236(65.6)$ & 1.00 & - & - & \\
\hline G & $129(37.5)$ & $124(34.4)$ & $1.14(0.84-1.56)$ & 0.432 & - & \\
\hline CD1D rs859009 & & & & & & 0.000 \\
\hline \multicolumn{7}{|l|}{ Codominant } \\
\hline GG & $46(26.7)$ & $29(16.1)$ & 1.00 & - & - & \\
\hline GC & $97(56.4)$ & $123(68.3)$ & $0.50(0.29-0.86)$ & 0.011 & 0.033 & \\
\hline $\mathrm{CC}$ & $29(16.9)$ & 28 (15.6) & $0.65(0.32-1.31)$ & 0.287 & - & \\
\hline \multicolumn{7}{|l|}{ Dominant } \\
\hline GG & $46(26.7)$ & $29(16.1)$ & 1.00 & - & - & \\
\hline $\mathrm{GC}+\mathrm{CC}$ & $126(73.3)$ & $151(83.9)$ & $0.53(0.31-0.88)$ & 0.019 & 0.057 & \\
\hline \multicolumn{7}{|l|}{ Recessive } \\
\hline $\mathrm{GG}+\mathrm{GC}$ & $143(83.1)$ & $152(84.4)$ & 1.00 & - & - & \\
\hline $\mathrm{CC}$ & $29(16.9)$ & $28(15.6)$ & $1.10(0.63-1.92)$ & 0.773 & - & \\
\hline \multicolumn{7}{|l|}{ Alleles } \\
\hline $\mathrm{G}$ & $189(54.9)$ & $181(50.3)$ & 1.00 & - & - & \\
\hline $\mathrm{C}$ & $155(45.1)$ & 179 (49.7) & $0.82(0.61-1.11)$ & 0.227 & - & \\
\hline CD1D rs 859010 & & & & & & 0.183 \\
\hline \multicolumn{7}{|l|}{ Codominant } \\
\hline AA & $89(51.8)$ & $105(58.4)$ & 1.00 & - & - & \\
\hline $\mathrm{AT}$ & $73(42.4)$ & $69(38.3)$ & $1.25(0.80-1.94)$ & 0.322 & - & \\
\hline $\mathrm{TT}$ & $10(5.8)$ & $6(3.3)$ & $1.97(0.74-5.61)$ & 0.297 & - & \\
\hline \multicolumn{7}{|l|}{ Dominant } \\
\hline AA & $89(51.8)$ & 105 (58.4) & 1.00 & - & - & \\
\hline $\mathrm{AT}+\mathrm{TT}$ & $83(48.2)$ & 75 (41.6) & $1.31(0.86-1.98)$ & 0.239 & - & \\
\hline \multicolumn{7}{|l|}{ Recessive } \\
\hline $\mathrm{AA}+\mathrm{AT}$ & 154 (89.6) & $169(93.9)$ & 1.00 & - & - & \\
\hline $\mathrm{TT}$ & $18(10.4)$ & $11(6.1)$ & $1.80(0.84-4.10)$ & 0.175 & - & \\
\hline \multicolumn{7}{|l|}{ Alleles } \\
\hline A & $251(72.9)$ & $279(77.5)$ & 1.00 & & & \\
\hline $\mathrm{T}$ & $93(27.1)$ & $81(22.5)$ & $1.28(0.91-1.79)$ & 0.190 & - & \\
\hline
\end{tabular}

The association was performed using logistic regression analysis. HWE was tested by $\chi^{2}$ test. OR, odds ratio; CI, confidence interval; $\mathrm{P}^{\mathrm{C}}$, Bonferroni corrected P-value; HWE, Hardy-Weinberg equilibrium.

all nucleated cells, the CD1 groups are expressed only on The human CD1 proteins present lipid antigens of MTB to APCs, cortical thymocytes and dendritic cells (DC) (10,26). T cells (27). Mounting evidence revealed a link between 
Table IV. Haplotype association of CD1A (rs411089 and rs366316) and CD1D (rs973742, rs859009 and rs859010) variants with pulmonary tuberculosis risk.

\begin{tabular}{lcccccccc}
\hline rs411089 & rs366316 & rs973742 & rs859009 & rs859010 & $\begin{array}{c}\text { Cases } \\
\text { (frequency) }\end{array}$ & $\begin{array}{c}\text { Control } \\
\text { (frequency) }\end{array}$ & $\begin{array}{c}\text { OR } \\
(95 \% \text { CI) }\end{array}$ & P-value \\
\hline C & A & G & G & A & 0.1133 & 0.1432 & 1.00 & - \\
T & G & A & C & A & 0.1522 & 0.1241 & $0.32(0.13-0.75)$ & 0.0092 \\
C & A & A & C & A & 0.0836 & 0.1096 & $1.22(0.46-3.27)$ & 0.69 \\
T & A & A & G & T & 0.0517 & 0.0804 & $0.86(0.31-2.41)$ & 0.78 \\
C & A & A & G & T & 0.0588 & 0.0632 & $0.97(0.34-2.75)$ & 0.96 \\
C & A & G & C & A & 0.0659 & 0.0598 & $0.47(0.15-1.46)$ & 0.19 \\
T & G & G & C & A & 0.0674 & 0.0587 & $0.79(0.20-3.11)$ & 0.74 \\
T & A & A & C & A & 0.0679 & 0.0419 & $0.14(0.02-0.89)$ & 0.038 \\
T & G & A & G & T & 0.0307 & 0.0409 & $0.75(0.17-3.30)$ & 0.7 \\
T & A & A & G & A & 0.0634 & 0.0407 & $0.12(0.03-0.57)$ & 0.0076 \\
C & A & A & G & A & 0.072 & 0.0378 & $0.99(0.17-5.86)$ & 1 \\
T & G & A & G & A & NA & 0.0296 & $1.16(0.24-5.53)$ & 0.85 \\
C & G & A & C & A & NA & 0.0283 & $0.99(0.08-11.45)$ & 0.99 \\
T & G & A & C & T & 0.0384 & 0.0189 & $0.91(0.11-7.40)$ & 0.93 \\
C & G & A & G & A & 0.0166 & 0.0186 & $0.40(0.06-2.70)$ & 0.35
\end{tabular}

Haplotype analysis was executed using SNPStats software. Each row represents separate polymorphisms. CD, cluster of differentiation.

CD1 polymorphisms and certain autoimmune and inflammatory diseases including inflammatory neuropathies (12), tuberculosis (14), cancer (28), multiple sclerosis $(16,29)$, and Guillain-Barre syndromes (30). In the current study the possible association between CD1 and the risk pf PTB in a sample of a southeast Iranian population was investigated. The results of the present study indicated that CD1A rs411089 as well as CD1D rs859009 variant was significantly associated with the risk of PTB. The CC genotype of CD1A rs411089 polymorphism in recessive model increased the risk of $\mathrm{PTB}$, while the GC genotype as well as GC+CC genotype of CD1D rs859009 polymorphism significantly decreased the risk of PTB.

To the best of the authors' knowledge, only one study has been performed on the impact of CD1 gene variants on the susceptibility to TB (14). Seshadri et al (14) in a case-population study genotyped rs366316, rs2269714, rs411089 and rs389293 in a discovery cohort of 352 cases and 382 controls. They identified that the rs366316 and rs411089 polymorphisms were significantly associated with the development of TB. In a next step they genotyped rs366316 and rs411089 in a validation cohort of 339 cases and 376 controls and another time discovered a significant association between rs411089 and TB, however they did not find any association between rs366316 and TB (14). In agreement with the results of the present study they demonstrated that the minor homozygous genotype of rs411089 was associated with an increased risk of $\mathrm{TB}$ in a recessive model (14). It seems that the minor homozygous genotype of rs411089 accompanied with a functional CD1A-deficiency and this polymorphism cause a low CD1A expression level. Sieling et al (31) demonstrated an increased expression of CD1 proteins (CD1A, CD1B and CD1C) at the site of tuberculoid leprosy lesions. Buettner et al (32) detected DCs in bronchoalveolar lavage specimens of tuberculosis patients with strongly upregulated of CD1A, CD83 and CCR7. Roura-Mir et al (33) have identified that MTB or its cell wall lipids caused increased expression level of CD1A, CD1B and CD1C but not CD1D. CD1A-deficient cells failed to present mycobacterium peptides to T cells. Behar et al (34) demonstrated that CD1D-deficient mice were not significantly different in their susceptibility to infection compared with control mice. This information demonstrates the use of a population genetics study to understanding the role of CD1 antigen-presenting molecules in human disease.

It has been reported that the rs366316 variant which is located in the in the promoter region is strongly associated with low CD1a surface expression (18). The rs411089, an intronic variant, is strongly linked to rs858998 and may regulate transcription independently of rs366316 (14). rs973742 is located 4-kb downstream from the CD1D gene and the functional role of this variant is unknown (35). The impact of intronic rs859009 and rs859010 polymorphisms on CD1D expression has not been recognized.

There is no clear explanation for the departure from HWE in the study population regarding rs411089, rs973742 and rs859009 polymorphisms. It may be owing to a small sample size, genetic drift or consanguineous marriages, which is common in this region of the country.

A limitation of this study is that there is no data regarding smoking, diabetes mellitus, socioeconomic status and other risk factor for PTB.

In conclusion, the results of the present study revealed that CD1A (rs411089) and CD1D (rs859009) polymorphisms protect against PTB in a sample of the Iranian population. More well-designed studies in diverse ethnicities are necessary to verify the present results. 


\section{Acknowledgements}

We would like to thank all individuals who participated in the study.

\section{Funding}

The present study was supported by the Deputy for research, Zahedan University of Medical Sciences, Zahedan, Iran (grant no. 7033).

\section{Availability of data and materials}

All data generated or analyzed during the present study are included in this published article.

\section{Authors' contributions}

MT, MH conceived and designed the study; HD, FB and GB performed the experiments and analyzed the data; MN performed data collection. All authors contributed to the writing of the manuscript and reviewed and approved the final manuscript.

\section{Ethics approval and consent to participate}

The local Ethics Committee of the Zahedan University of Medical Sciences approved the project and written informed consent was taken from all participants.

\section{Patient consent for publication}

Not applicable.

\section{Conflict of interest}

The authors declare no conflict of interest. The abstract of the present study was previously presented at a conference (https:// www.nature.com/articles/s41431-018-0248-6).

\section{References}

1. Smith I: Mycobacterium tuberculosis pathogenesis and molecular determinants of virulence. Clin Microbiol Rev 16: 463-496, 2003.

2. Harishankar M, Selvaraj P and Bethunaickan R: Influence of Genetic Polymorphism Towards Pulmonary Tuberculosis Susceptibility. Front Med (Lausanne) 5: 213, 2018.

3. WHO: Global Tuberculosis Report 2017. World Health Organization, 2017.

4. Wei Z, Wenhao S, Yuanyuan M, Yang L, Daming Z, Jiangchun X and Jijun J: A single nucleotide polymorphism in the interferon- $\gamma$ gene (IFNG +874 T/A) is associated with susceptibility to tuberculosis. Oncotarget 8: 50415-50429, 2017.

5. Naderi M, Hashemi $M$ and Ansari H: Macrophage migration inhibitory factor $-173 \mathrm{G}>\mathrm{C}$ polymorphism and risk of tuberculosis: A meta-analysis. EXCLI J 16: 313-320, 2017.

6. Barral DC and Brenner MB: CD1 antigen presentation: How it works. Nat Rev Immunol 7: 929-941, 2007.

7. Brigl M and Brenner MB: CD1: Antigen presentation and T cell function. Annu Rev Immunol 22: 817-890, 2004.

8. Aureli A, Oumhani K, Del Beato T, Di Rocco M, Tessitore A, El Aouad R and Piancatelli D: Increased CD1D polymorphism: Identification of two novel alleles, CD1D*03 and $* 04$, in individuals from Morocco. Int J Immunogenet 42: 287-291, 2015.
9. Chancellor A, Gadola SD and Mansour S: The versatility of the CD1 lipid antigen presentation pathway. Immunology 154: 196-203, 2018

10. Siddiqui S, Visvabharathy L and Wang CR: Role of group 1 CD1-restricted T cells in infectious disease. Front Immunol 6: 337, 2015.

11. Van Rhijn I and Moody DB: CD1 and mycobacterial lipids activate human T cells. Immunol Rev 264: 138-153, 2015.

12. Uncini A, Notturno F, Pace M and Caporale CM: Polymorphism of CD1 and SH2D2A genes in inflammatory neuropathies. J Peripher Nerv Syst 16 (Suppl 1): 48-51, 2011.

13. Huang S: Targeting Innate-Like T Cells in Tuberculosis. Front Immunol 7: 594, 2016

14. Seshadri C, Thuong NT, Yen NT, Bang ND, Chau TT, Thwaites GE, Dunstan SJ and Hawn TR: A polymorphism in human CD1A is associated with susceptibility to tuberculosis. Genes Immun 15: 195-198, 2014

15. DeWitt WS, Yu KKQ, Wilburn DB, Sherwood A, Vignali M, Day CL, Scriba TJ, Robins HS, Swanson WJ, Emerson RO, et al: A diverse lipid antigen-specific TCR repertoire is clonally expanded during active tuberculosis. J Immunol 201: 888-896, 2018.

16. Caporale CM, Notturno F, Pace M, Aureli A, Di Tommaso V, De Luca G, Farina D, Giovannini A and Uncini A: CD1A and CD1E gene polymorphisms are associated with susceptibility to multiple sclerosis. Int J Immunopathol Pharmacol 24: 175-183, 2011.

17. Kuijf ML, Geleijns K, Ennaji N, van Rijs W, van Doorn PA and Jacobs BC: Susceptibility to Guillain-Barré syndrome is not associated with CD1A and CD1E gene polymorphisms. J Neuroimmunol 205: 110-112, 2008.

18. Seshadri C, Shenoy M, Wells RD, Hensley-McBain T, Andersen-Nissen E, McElrath MJ, Cheng TY, Moody DB and Hawn TR: Human CD1a deficiency is common and genetically regulated. J Immunol 191: 1586-1593, 2013.

19. Lundtoft C, Awuah AA, Güler A, Harling K, Schaal H, Mayatepek E, Phillips RO, Nausch N, Owusu-Dabo E and Jacobsen M: An IL7RA exon 5 polymorphism is associated with impaired IL-7R $\alpha$ splicing and protection against tuberculosis in Ghana. Genes Immun: Oct 31, 2018 (Epub ahead of print). doi: 10.1038/s41435-018-0049-5.

20. Hashemi M, Eskandari-Nasab E, Moazeni-Roodi A, Naderi M, Sharifi-Mood B and Taheri M: Association of CTSZ rs34069356 and MC3R rs6127698 gene polymorphisms with pulmonary tuberculosis. Int J Tuberc Lung Dis 17: 1224-1228, 2013.

21. Naderi M, Hashemi M, Safdari A, Bahari G and Taheri M: Association of genetic polymorphisms of CISH with the risk of pulmonary tuberculosis in Zahedan, Southeast Iran. Braz J Infect Dis 20: 379-383, 2016.

22. Naderi M, Hashemi M and Amininia S: Association of TAP1 and TAP2 gene polymorphisms with susceptibility to pulmonary tuberculosis. Iran J Allergy Asthma Immunol 15: 62-68, 2016.

23. Naderi M, Hashemi M, Pourmontaseri Z, Eskandari-Nasab E, Bahari G and Taheri M: TIRAP rs8177374 gene polymorphism increased the risk of pulmonary tuberculosis in Zahedan, southeast Iran. Asian Pac J Trop Med 7: 451-455, 2014.

24. Hashemi M, Hanafi Bojd H, Eskandari Nasab E, Bahari A, Hashemzehi NA, Shafieipour S, Narouie B, Taheri M and Ghavami S: Association of adiponectin rs1501299 and rs266729 gene polymorphisms with nonalcoholic fatty liver disease. Hepat Mon 13: e9527, 2013.

25. Solé X, Guinó E, Valls J, Iniesta R and Moreno V: SNPStats: A web tool for the analysis of association studies. Bioinformatics 22: 1928-1929, 2006

26. Ulrichs T, Moody DB, Grant E, Kaufmann SH and Porcelli SA: T-cell responses to CD1-presented lipid antigens in humans with Mycobacterium tuberculosis infection. Infect Immun 71: 3076-3087, 2003.

27. Seshadri C, Thuong NT, Mai NT, Bang ND, Chau TT, Lewinsohn DM, Thwaites GE, Dunstan SJ and Hawn TR: A polymorphism in human MR1 is associated with mRNA expression and susceptibility to tuberculosis. Genes Immun 18: 8-14, 2017.

28. Golmoghaddam H, Pezeshki AM, Ghaderi A and Doroudchi M: CD1a and CD1d genes polymorphisms in breast, colorectal and lung cancers. Pathol Oncol Res 17: 669-675, 2011.

29. Jamshidian A,Nikseresht AR, Vessal M and Kamali-SarvestaniE: Association of CD1A +622 T/C, $+737 \mathrm{G} / \mathrm{C}$ and CD1E +6129 A/G genes polymorphisms with multiple sclerosis. Immunol Invest 39: 874-889, 2010. 
30. Liu H, Xing Y, Guo Y, Liu P, Zhang H, Xue B, Shou J, Qian J, Peng J, Wang R, et al: Polymorphisms in exon 2 of CD1 genes are associated with susceptibility to Guillain-Barré syndrome. J Neurol Sci 369: 39-42, 2016.

31. Sieling PA, Jullien D, Dahlem M, Tedder TF, Rea TH, Modlin RL and Porcelli SA: CD1 expression by dendritic cells in human leprosy lesions: Correlation with effective host immunity. J Immunol 162: 1851-1858, 1999.

32. Buettner M, Meinken C, Bastian M, Bhat R, Stössel E, Faller G, Cianciolo G, Ficker J, Wagner M, Röllinghoff M, et al: Inverse correlation of maturity and antibacterial activity in human dendritic cells. J Immunol 174: 4203-4209, 2005.
33. Roura-Mir C, Wang L, Cheng TY, Matsunaga I, Dascher CC, Peng SL, Fenton MJ, Kirschning $C$ and Moody DB: Mycobacterium tuberculosis regulates CD1 antigen presentation pathways through TLR-2. J Immunol 175: 1758-1766, 2005.

34. Behar SM, Dascher CC, Grusby MJ, Wang CR and Brenner MB: Susceptibility of mice deficient in CD1D or TAP1 to infection with Mycobacterium tuberculosis. J Exp Med 189: 1973-1980, 1999.

35. Barbier M, Sabbagh A, Kasper E, Asheuer M, Ahouansou O, Pribill I, Forss-Petter S, Vidaud M, Berger J and Aubourg P: $\mathrm{CD} 1$ gene polymorphisms and phenotypic variability in X-linked adrenoleukodystrophy. PLoS One 7: e29872, 2012. 